\title{
MIOPIAS DE UMA LENTE DE AUMENTO: AS LIMITACOOES DA ANÁLISE DE DOCUMENTOS NO ESTUDO DAS ORGANIZACÕES
}

\author{
SHORT-SIGHTEDNESS THROUGH A MAGNIFYING GLASS: THE LIMITATIONS OF DOCUMENT \\ ANALYSIS IN THE STUDY OF ORGANIZATIONS \\ MIOPÍAS DE UNA LENTE DE AUMENTO: LAS LIMITACIONES DEL ANÁLISIS DE DOCUMENTOS EN \\ EL ESTUDIO DE LAS ORGANIZACIONES
}

\author{
Julio Araujo Carneiro da Cunha \\ Doutor \\ Universidade Paulista (UNIP) \\ Juliocunha@yahoo.com.br \\ Cesar Akira Yokomizo \\ Doutorando \\ Fundação Getulio Vargas (FGV) \\ Cesar.yokomizo@gmail.com
}

Carlos Alberto Grespan Bonacim

Doutor

Universidade de São Paulo

carlosbonacim@yahoo.com.br

Submetido em: 07/10/2012

Aprovado em: 16/07/2013

\section{RESUMO}

As publicações nacionais na área da Administração, muitas vezes, recorrem ao estudo de caso como estratégia metodológica para a pesquisa de campo, que comumente apoiam-se na tríade: entrevista, observação e análise de documentos. Destas, foca-se, especificamente, na análise de documentos, a fim de se incrementar o rigor desse método de coleta de informações. Diante disso, o intuito da presente discussão é identificar as limitações da análise de documentos nos estudos das organizações, a fim de advertir os pesquisadores sobre os riscos existentes, para que uma pesquisa sob esse método detenha o rigor adequado. É importante entender que o processo de análise de documentos não é único, sendo complemento ou complementado por outros métodos coleta de dados. Por isso, uma análise de documentos com maior rigor exige atividades prévias por parte do pesquisador. Essas atividades envolvem reflexões e compreensão do pesquisador sobre: (1) o contexto social; (2) o indivíduo escritor do documento; (3) a elaboração do documento por parte do escritor; (4) a leitura do texto do documento; (5) o leitor; (6) o documento per se. A partir dessa sistemática, o pesquisador pode se deparar com os seguintes problemas: (a) contexto social ao qual o documento foi elaborado; (b) conhecimento prévio que o pesquisador pode deter para abstrair maiores informações do documento; (c) conteúdo preestabelecido, que limita a percepção do pesquisador quanto ao conteúdo do documento; (d) retórica contida no documento, que pode enviesar a interpretação da realidade da organização; (e) documento como fonte única de dados, que estabelece que o documento pode ser complementado por outros métodos de coleta de dados. A falta de preparo e de atenção em relação a todos esses elementos pode comprometer a compreensão da estrutura do documento e, principalmente, do seu conteúdo e discurso. Com essas precauções, acredita-se que os pesquisadores possam levantar com maior rigor informações empíricas por meio de análises documentais. 
PALAVRAS-ChAVES: Análise documental. Análise de documentos. Método de pesquisa.

\begin{abstract}
Brazilian publications in the area of Business Management are often supported by a case study, a methodological strategy used in field research, which often relies on the triad: interview, observation and document analysis. From these three methods of data collection, this research focuses specifically on document analysis, seeking to overcome the lack of rigor in this method of gathering information. Therefore, the purpose of this discussion is to identify the limitations of document analysis in the studies of organizations, and to make researchers aware of the risks of this method, to ensure that research carried out using this method maintains the necessary rigor. It is important to understand that the process of document analysis does not stand alone, but is complementary to, or complemented by other data collection methods. Hence, a document analysis with high levels of rigor requires prior activities on the part of the researcher. These activities involve reflections and understanding of the researcher about: (1) the social context; (2) the individual who wrote the document; (3) the way the document is written; (4) the reading of the text; (5) the reader; and (6) the document per se. Based on these factors, the researcher may come across the following problems: (a) the social context in which the document was written; (b) prior knowledge that the researcher may have to abstract greater information from the document; (c) pre-established content that can limit the researcher's perception of the content of the document; (d) the rhetorical content of the document, which can bias the interpretation of the organizational reality; (e) the document as a single source of data, establishing that the document can be complemented by other data collection methods. The lack of preparation and attention in relation to all these elements can compromise the understanding of the structure of the document and, in particular, its content and discourse. With these precautions, we believe that researchers can raise more rigorously empirical information through document analysis.
\end{abstract}

KEYWORDS: Document analysis. Document analysis. Search Method.

\title{
RESUMEN
}

Las publicaciones nacionales en el área de la Administración muchas veces recurren al estudio de caso como estrategia metodológica para la investigación de campo, que comúnmente se apoya en la tríada: entrevista, observación y análisis de documentos. Entre estas, se concentra específicamente en el análisis de documentos, a fin de incrementar el rigor de ese método de recolección de informaciones. Frente a este panorama, la intención de la presente discusión es identificar las limitaciones del análisis de documentos en los estudios de las organizaciones a fin de advertir a los investigadores sobre los riesgos existentes, para que una investigación con ese método tenga el rigor adecuado. Es importante entender que el proceso de análisis de documentos no es único, siendo complemento o complementado por otros métodos de recolección de datos. Por eso, un análisis de documentos con mayor rigor exige actividades previas por parte del investigador. Esas actividades involucran reflexiones y comprensión del investigador sobre: (1) el contexto social; (2) el individuo escritor del documento; (3) la elaboración del documento por parte del escritor; (4) la lectura del texto del documento; (5) el lector; (6) el documento per se. A partir de esa sistemática, el investigador puede depararse con los siguientes problemas: (a) el contexto social en el cual el documento fue elaborado; (b) el conocimiento previo que el investigador pueda poseer para extraer mayores informaciones del documento; (c) el contenido preestablecido, que limita la percepción del investigador en relación al contenido do documento; (d) la retórica contenida en el documento, que puede sesgar la interpretación de la realidad de la organización; (e) el documento como fuente única de datos, que establece que el documento puede ser complementado por otros métodos de recolección de datos. La falta de preparación y de atención en relación a todos esos elementos puede comprometer la 
comprensión de la estructura del documento y principalmente de su contenido y discurso. Se estima que con estas precauciones los investigadores podrán levantar con mayor rigor informaciones empíricas por medio de análisis documentales.

PALABRAS CLAVE: Análisis documental. Análisis de documentos. Método de investigación.

"A leitura do mundo precede a leitura da palavra" (Paulo Freire)

\section{INTRODUÇÃO}

As pesquisas na área de Administração, sobretudo em seu início como ciência, caracterizaram-se por terem procedimentos metodológicos altamente objetivos. Esse pensamento positivista sobre as atividades organizacionais deixou como legado uma linha de pensamento quantitativo que perdura até os dias de hoje. A linha quantitativa prega o rigor metodológico e supostamente, portanto, resultados e análises menos subjetivos e menos sujeitos a dúvidas, a críticas ou a questionamentos.

Muitos desses métodos positivistas foram originados nas pesquisas das chamadas ciências naturais, em uma transposição de procedimentos que tentavam entender as organizações dentro de preceitos válidos especificamente para aquelas ciências. No entanto, o que se constatou ao longo dos anos foi que os paradigmas rígidos das ciências naturais (hard sciences) não eram totalmente replicáveis nas pesquisas de ciências sociais (soft sciences), dando margem à emergência do relativismo epistemológico, como apregoam Bertero, Caldas e Wood Jr. (2005). Como resultado, os métodos consagrados das ciências naturais não atendiam às realidades dos fenômenos sociais das organizações, pois apresentavam limitações ao abordar as especificidades das estruturas sociais e seu funcionamento dinâmico. A pesquisa social aplicada à Administração deveria ser capaz de compreender fenômenos pelas relações causais internas e observar a particularidade de casos, em vez de se buscar incessantemente uma regra geral para os fenômenos (WHITLEY, 1984).

Como consequência dessa constatação, o que se verificou foi o advento de uma linha de pensamento mais qualitativa (parte em contraposição, parte em complemento à linha mais quantitativa). Prova disso é a emergência e o crescimento de um número cada vez maior de pesquisas acadêmicas que fizeram uso de procedimentos metodológicos próprios, buscando compreender relações, causas e justificativas que pudessem suportar um melhor entendimento dos acontecimentos inerentes aos fenômenos sociais. Assim, formas até então não tradicionais de pesquisa que se apoiavam em métodos qualitativos, gradativamente, ganharam espaço nos estudos das ciências sociais (DWYTHER; PASSAMAI-INESEDY, 2009), mesmo que, por vezes, se perdurasse o desafio desses métodos em conseguir demonstrar sua validade e rigor no levantamento de informações de campo (SUTTON, 1997).

Especificamente nos estudos das organizações, pesquisas qualitativas têm se sustentado bastante na estratégia de pesquisa do estudo de caso (STAKE, 2000), em especial, desde as décadas de 1980 e início da década de 1990 (CAMPOMAR, 1991). A partir de então, essa estratégia de pesquisa ganhou maiores proporções daí em diante em diversas áreas da Administração (para exemplos, ver Stablein, 2001; Hocayen da Silva, Rossoni e Ferreira, 2006; Rossoni e Hocayen da Silva, 2007; Sobral e Mansur, 2013). No entanto, o grande entrave dessa estratégia repousa na dificuldade para se obter legitimidade (falta de rigor metodológico) na coleta de dados empírica, na sua interpretação e, consequentemente, nos resultados obtidos (POZZEBON; FREITAS, 1998; YIN, 2008), desafio que até hoje perdura nos estudos das organizações, especialmente no Brasil: "em muitos casos, a análise do material empírico é fraca, mascarada por tonalidades prescritivas, e há pouco esforço de abstração do pesquisador tanto para generalizar práticas, como para criar teoria local" (ROESCH, 2005, p. 166). Essa situação agrava-se porque a sistemática imposta pelo estilo de ciência atualmente instituído torna difícil, por parte das ciências sociais aplicadas, prover resultados relevantes e, ao mesmo tempo, que tenham rigor (KIESER; LEINER, 2009). Isso vale para todos os métodos de coleta de dados dos estudos de caso, tal como propõe Yin (2008): análise documental; análise de documentação de arquivo; entrevista; observação direta; observação participante; análise sobre artefatos físicos. 
Esses métodos de coleta de dados poderiam incrementar ainda mais seu rigor, conferindo assim maior legitimidade para os resultados encontrados. Dentre elas, este artigo pretende aprofunda-se na análise de documentos ou análise documental, pois ela é uma das que menos apresenta aparatos para validar seu rigor nas pesquisas de campo. Isso ocorre não apenas porque o rigor na análise de documentos tem espaço para ser incrementado, mas também porque é um método o qual, comumente, novatos em pesquisa recorrem, realizando pesquisas por meio dele ainda de forma pouco madura (BOWEN, 2009), além de ser pouco discutido entre os pesquisadores de ciências sociais (PRIOR, 2010), gerando assim, relativamente, menor reflexão sobre o método.

A análise de documentos como método de coleta de dados, até anos atrás, tinha muito espaço para maiores explorações (LEVY, 1988) e à medida que o interesse por esse tipo de pesquisa demonstrou-se crescente (BERNARD; RYAN, 1998), essas tendências exigiram, concomitantemente, um desenvolvimento metodológico capaz de dar suporte a essa evolução. Trata-se, portanto, de um método de pesquisa emergente (ALTHEIDE et al., 2010; PRIOR, 2010) e que precisa de formas adequadas e de rigor para a interpretação dos dados contidos nesses documentos. "Supõe-se que a necessidade de tratamento e interpretação dos materiais decorrentes, ou seja, dos textos obtidos, requeira aparato metodológico que subsidie de maneira sólida as conclusões a serem alcançadas" (DELLAGNELO; SILVA, 2007, p. 97). Ou seja, deve haver um método de abordagem ao documento que permita ao pesquisador obter dados com rigor e validade que sejam capazes de sustentar suas análises e os subsequentes resultados da pesquisa. É importante que esse método de pesquisa seja epistemologicamente relativizado ao contexto da organização ao mesmo passo em que necessita demonstrar o rigor metodológico adequado, evitando possíveis armadilhas das limitações desse método específico (dado que todos os métodos de pesquisa têm seus prós e contras). Os pesquisadores de ciências sociais devem estar atentos, porque a melhoria do rigor desse método de pesquisa passa não apenas pelo "como fazer" uma análise documental, mas também ao "como não fazer" e "quais problemas evitar" durante essa etapa de análise da pesquisa. O presente estudo foca-se, especificamente, na vertente do que evitar e quais barreiras o pesquisador deve estar atento quando for analisar documentos nos estudos das organizações.

Diante da importância desse método de pesquisa para os estudos das organizações, o objetivo do presente ensaio teórico é o de evidenciar possíveis limitações da análise de documentos como método de coleta de dados nas pesquisas dos estudos das organizações a fim de advertir os pesquisadores dos riscos existentes para que uma pesquisa sob esse método detenha o rigor adequado, bem como o de apontar caminhos para a excelência no uso de dados documentais. A seguir, serão apresentados os principais conceitos teóricos identificados em uma revisão bibliográfica sobre o tema, capazes de oferecerem construtos para a compreensão e para a identificação dessas limitações da análise de documentos.

\section{CONCEITOS SOBRE A ANÁLISE DE DOCUMENTOS}

Os documentos a serem analisados podem conter tanto conteúdo escrito, em forma de texto, quanto imagens representadas por figuras (SILVERMAN, 2009). Patton (2002) lista as formas mais tradicionais de documentos: materiais escritos dos registros da organização; memorandos e correspondências; publicações e notificações oficiais; diários pessoais, cartas, trabalhos artísticos, fotos e lembranças físicas; respostas escritas de questionários públicos.

Entretanto, no contexto das organizações, grande parte das documentações segue padrões formais estabelecidos pelos profissionais de negócios, de maneira que a maioria dos documentos se apresenta na forma escrita. Não obstante, a análise de documentos pode ser feita por meio de documentos eletrônicos ou documentos físicos pertencentes ao cotidiano das organizações (CASEY; WONG, 1990).

Bernard e Ryan (1998) diferenciam as tradições de estudos e pesquisas sobre as documentações e seus textos. Para os autores, existe uma tradição linguística de estudo na qual o texto é tratado como o próprio objeto de análise; uma segunda vertente relacionada à tradição sociológica de análise de texto trata-o como uma janela para as experiências humanas.

No primeiro caso, o documento per se é elemento suficiente para alimentar as necessidades que envolvem o objeto de estudo. Isso é o que acontece em áreas como a História, o Jornalismo 
ou a Antropologia, que recorrem ao conteúdo de documentos formalizados para verificar aspectos e fatos históricos de uma situação ou fenômeno. A análise de documentos é especialmente importante em estudos históricos, pois o registro formalizado pode ser uma das poucas pistas do passado e, dentre elas, a mais confiável e intacta pelo tempo em termos de conteúdo; por vezes, a análise de documentos é a única fonte de dados disponível para evidenciar pesquisas históricas.

No segundo caso, e mais presente nos estudos das organizações, a análise documental é realizada não apenas com base no conteúdo escrito dos documentos, mas também considerando as significações por trás das palavras e, por isso, é inevitável que exista um ranço sociológico nesse tipo de análise. O pesquisador nesses casos pretende justamente entender significações, relações e compreender fenômenos. No entanto, a análise de documentos pode ser uma barreira natural para o total entendimento do fenômeno quando o pesquisador desconhece o meio social no qual o documento foi escrito. Não se pode deixar de mencionar que, embora o documento possa servir de respaldo para a coleta de dados empíricos, eles não respondem a todos os questionamentos desse tipo de pesquisa.

Por isso, é fundamental entender que, no caso dos estudos das organizações, a análise de documentos está inserida dentro de um contexto social. Por outro lado, compreender esse contexto somente por meio de documentos não é uma tarefa trivial e, por isso, muitas vezes, métodos adicionais de coletas de dados são necessários para a adequada compreensão do fenômeno que está sendo estudado.

\section{O TEXTO ESCRITO CONTIDO NO DOCUMENTO}

Consoante com a tradição sociológica, é fácil entender que a análise de documentos, na grande maioria das vezes, acaba sendo guiada pelas técnicas de análise de conteúdo, análise de discurso ou ainda análise de narrativa (MARTINS; THEÓPHILO, 2007). São recursos importantes para as ciências sociais porque analisam os dados como representações de eventos que não são físicos; pelo contrário, esses eventos estão representados em textos, imagens e expressões criados para serem lidos, vistos e interpretados e que podem ter impactos diferentes na mente das pessoas que receberão a mensagem (KRIPPENDORFF, 2004).

Essa análise com enfoque no conteúdo escrito do documento pode ter cunho quantitativo, qualitativo ou ser uma mistura de ambos, já que não são excludentes. É qualitativo quando seu foco está nas peculiaridades ou, ainda, nas relações dos elementos contidos do documento. É quantitativo quando privilegia as frequências de determinados termos ou palavras-chave. No entanto, o que ocorre, na maioria das vezes, são pesquisas com dados reduzidos, em relativa pouca quantidade e de maneira não estruturada. Nesse contexto, é mais apropriado que métodos qualitativos sejam utilizados.

Comumente, a análise de conteúdo é a técnica que se recorre na análise de documentos para que se possam sistematizar, de forma objetiva, os dados desestruturados contidos no manifesto analisado, de maneira a quantificá-los. Assim, tem-se uma estruturação que reduz a dependência da subjetividade do leitor para a compreensão do conteúdo, diminuindo a influência dos valores culturais, crenças e preconceitos que o pesquisador pode ter no momento da sua leitura (POZZEBON et al., 1997).

Concomitantemente, a análise de conteúdo realizada por completo se preocupa ainda em investigar o conteúdo de textos dentro do contexto de uso deles (KRIPPENDORFF, 2004). Exemplificando um caso dos estudos das organizações, uma ciência social aplicada: o texto escrito por um executivo pode ser diferente quando é direcionado internamente e quando é um documento público, focado aos stackholders (FIOL, 1995). Isso implica que a análise documental deve levar em consideração também o ambiente no qual o documento foi gerado e o seu propósito.

No entanto, a análise do que está escrito por si só tem apresentado limitações porque, quando utilizada de forma isolada, traz resultados insuficientes para captar o contexto no qual determinado documento foi gerado (MANNING; CULLUM-SWAN, 1998). Portanto, dependendo da abordagem que o pesquisador adotar, ele pode não conseguir coletar essa informação e, consequentemente, a análise do que se tem escrito pode não ser suficiente e satisfatória. É por isso que se incentiva que a análise de documentos vá além do seu texto escrito, já que fatores extrínsecos ao texto escrito 
podem trazer informações relevantes ao pesquisador e esclarecedores para que ele possa tecer conclusões relevantes a respeito do fenômeno estudado.

Portanto, é importante considerar não apenas o texto escrito na análise de documentos. Existem outros aspectos qualitativos presentes no documento que não deveriam ser ignorados pelo pesquisador, na medida em que documentos podem ser produzidos, manipulados, usados e consumidos de maneira a criar um impacto em seus leitores, reagindo a favor (ou contra) seus elaboradores (PRIOR, 2004). Existem elementos incrementais na análise de conteúdo de documentos que podem ser considerados a partir: (1) do contexto social do documento, (2) da capacidade de compreensão do conteúdo, que varia de leitor a leitor e (3) da intencionalidade e do conteúdo disposto pelo escritor.

A Figura 1 representa as relações entre escritor, leitor, documento e contexto social no qual está imerso o escritor. Cada um desses elementos contidos na análise de documentos pode apresentar problemas para o pesquisador desatento ou oportunidades para o pesquisador rigoroso.

Figura 1 - A sistemática da análise de documentos

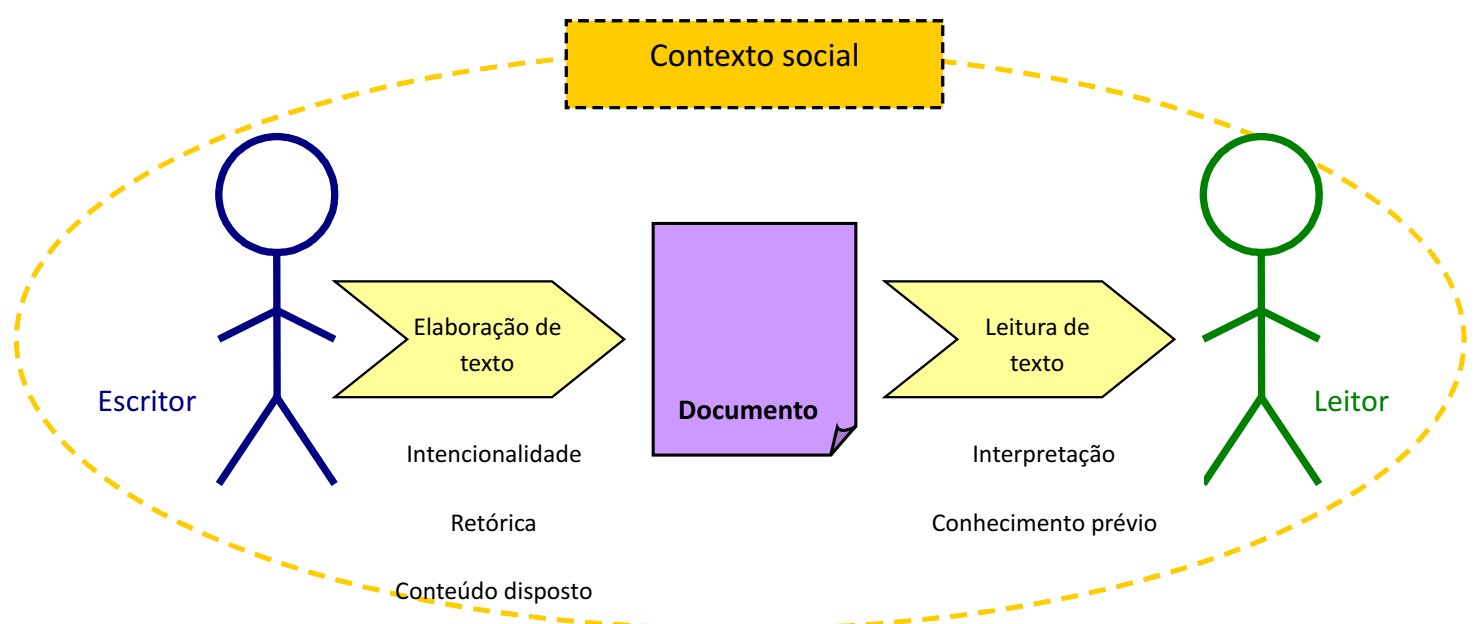

Fonte: Elaborado pelos autores.

Dessa forma, a sistemática da análise de documentos envolve quatro elementos-chave: (1) o escritor, que durante a elaboração do texto utiliza retórica para a representação de sua escrita, escreve com a intencionalidade direcionada ao que ele quer apontar e comunicar, e estabelece o conteúdo de seu texto, que é influenciado pela intencionalidade e pela retórica; (2) o documento em si, que é matéria-prima para coleta de dados; (3) o leitor, que lê esse documento e o interpreta conforme suas estruturas mentais, mindsets e conhecimentos prévios; e (4) o contexto social, que vai influenciar o escritor no seu processo de elaboração do texto do documento e vai influenciar as normas de formatação e de escrita do documento.

No entanto, essa sistemática de análise de documentos pode trazer consigo alguns problemas provenientes de algum dos quatro elementos-chave de sua sistemática. Esses problemas podem induzir o pesquisador (no papel de leitor) a incorrer em más interpretações ou armadilhas capazes de comprometer os dados obtidos por meio do documento. $O$ que se pôde levantar na literatura sobre o tema sobre esses problemas será apresentado nos itens a seguir, que são apresentados como miopias ${ }^{1}$ da análise de documentos.

\section{A MIOPIA DO CONTEXTO SOCIAL}

Segundo Prior (2004), os documentos escritos são produzidos dentro de um contexto específico, em que o escritor expõe seus pensamentos de maneira formalizada. Para a autora, existe um contexto que envolve a elaboração do documento, fazendo com que ele esteja inserido em um contexto socialmente organizado o que, seguramente, influencia a estrutura e o conteúdo do 
documento. Patton (2002) defende a mesma ideia, alegando que o dado capturado do documento deve preservar e gravar o contexto. Nas palavras de Silverman (2009, p. 159): "todos os documentos (...) são produzidos em circunstâncias específicas para audiências específicas. Os arquivos nunca falam por si só".

Prior (2004) ainda aponta que existe um propósito de uso do documento na rotina da organização, o que reforça a noção de contexto e dá indícios de seu formato e de seu conteúdo. Em outras palavras, os documentos não são formalizações únicas e isoladas dentro da organização, eles estão inseridos em um contexto e estão integrados com os fenômenos organizacionais.

É compreensível, pois, que o texto de um documento passe pelo círculo hermenêutico em sua compreensão. Ou seja, pela hermenêutica, a compreensão de um texto documental como um todo é estabelecida pela referência com as partes desse texto e vice-versa. Tem-se, assim, um ciclo em que nem a parte do texto e nem seu todo podem ser compreendidos sem se referenciarem.

Gadamer (1975) sintetiza a ideia da hermenêutica alegando que o conhecimento sobre algo depende das limitações interpretativas do pesquisador, que existem em decorrência das experiências vividas por ele e que o auxiliaram na construção de seus valores, pensamentos e mindsets. Para Álvaro e Garrido (2006, p. 321), "o conhecimento está sempre impregnado de subjetividade de quem conhece e é definido pelos limites de suas práticas interpretativas".

No entanto, mesmo que existam informações que são inerentes ao contexto de emergência do documento escrito, ainda assim, há uma limitação de caráter sociológico pela natureza das características sociais dos fenômenos. O contexto social é palco para eventos que o pesquisador dificilmente consegue interiorizar: são elementos implícitos e escondidos na sistemática social (BAUMAN, 2008), o que se agrava quando a forma de coleta de dados do pesquisador ocorre por meio do documento escrito e não pelo contato social. Em uma interação com outro indivíduo, algumas informações sociais poderiam ser compreendidas pelo pesquisador. Entretanto, para uma relação em que o intermediário do emissor (participante do contexto social) e do receptor (pesquisador) é o texto escrito, dificulta-se a transferência desses elementos escondidos na realidade sociológica.

\section{A MIOPIA DO CONHECIMENTO PRÉVIO}

Embasando-se na discussão da hermenêutica, considera-se que, apesar do conteúdo de um documento ser uma formalização dos pensamentos de seu escritor, nem sempre é possível abstrair a informação lida a ponto de absorver e captar por completo o conteúdo do documento. Muitas vezes, compreender o que foi descrito em um documento depende de uma construção simbólica, de linguagem e de conhecimentos prévios que possibilitem entender o que o emissor pretendeu transmitir, tal como as informações passíveis de serem coletadas de forma implícita, pela linguagem ou contexto do documento.

No mais, a própria escrita pode trazer significados além de suas representações semânticas, trazendo uma comunicação de caráter tácito, carregado de questões intrínsecas, como, por exemplo, a cultura e os valores, o que faz crer que existem significações além da mera análise de conteúdo dos documentos. Ou seja, o nível de compreensão de um documento depende de experiência, know-how, mindset e conhecimentos acumulados que o leitor aplica ao documento no momento da leitura e da interpretação. Nesse instante, o leitor recorre à sua própria bagagem intelectual, aplicando parâmetros de simbologias, tipificações e significações provenientes de seu estoque de conhecimentos aos documentos, gerando abstrações e compreensões pertinentes a essa carga de conhecimentos prévios.

Esse conhecimento armazenado na mente do leitor pode ser referente às estruturas cognitivas do conteúdo do documento, do contexto social ao qual o documento foi gerado e instituído ou ainda à própria estrutura de apresentação do documento. Em ambos os casos, o leitor que detém um conhecimento antecipado aplicado ao documento consegue abstrair um grau maior de informações.

Sobre a estrutura do documento, tem-se, por um lado, que o conhecimento existente de forma descrita no documento possa ser também planejado estruturalmente para que se consiga facilitar a 
recuperação do conhecimento contido no documento (SALMINEN, KAUPPINEN; LEHTOVAARA, 1997). Esse planejamento em um nível maior resultaria em uma padronização dos documentos corporativos dentro de templates e formatos que preestabelecidos, sendo capazes de expressar os sistemas que envolvem os atores e as atividades organizacionais (SALMINEN et al., 2000). No entanto, nem todo documento com que o pesquisador se defronta em sua jornada de campo está organizado. $\mathrm{Na}$ grande maioria das vezes, eles estão desorganizados, o que exige ainda mais do pesquisador e de suas habilidades para se identificar os elementos descritos no documento e compreendê-los de forma mais completa possível.

Ainda nessa linha de pensamento de Salminen et al. (2000), que defendem que os documentos podem facilitar a compreensão e os próprios processos de negócios quando estão padronizados, é importante lembrar que o desenvolvimento eficaz da padronização desses documentos depende da compreensão e adaptação desse padrão conforme o contexto em que o documento é criado e usado. Isso retoma ao fato de que, para o pesquisador compreender por completo um documento pesquisado, mesmo que ele esteja disposto dentro de padrões e de uma estrutura em que suas informações são mais facilmente capturadas, ele ainda precisaria entender o contexto de uso daquele documento para melhor compreender o que está por detrás dele.

Østerlund e Boland (2009), por exemplo, verificaram em um estudo empírico de prontuários hospitalares que a compreensão do conteúdo descrito nos documentos (prontuários), tal como o entendimento da linguagem e das abreviações utilizadas, dependia do conhecimento prévio do leitor sobre os itens relacionados à medicina e à cultura hospitalar. Ou seja, além de ser importante haver o conteúdo médico prévio para melhor compreender o que estava descrito no prontuário, o leitor que detém conhecimento cultural e experiência com prontuários, entende melhor as abreviações e as significações das escritas contidas nesses prontuários.

Para aqueles que conhecem elementos organizacionais como o contexto, a cultura e as significações contidos de forma implícita nos documentos, poucos dados (palavras) podem trazer uma gama de significados e assimilações muito maiores se comparado ao indivíduo que não detém esse conhecimento prévio sobre o contexto e os significados do documento. Por isso, quando o conhecimento prévio dos elementos sociais da organização é limitado por parte do pesquisador, a quantidade de elementos tácitos absorvidos é menor.

Isso se comprovou no estudo de Østerlund e Boland (2009), que demonstrou que, quando o leitor do documento recorre a conhecimentos prévios sobre o conteúdo descrito no documento, ele tem maior facilidade para compreender, abstrair e interiorizar esse conteúdo. Quando existem elementos que o leitor pode relacionar com suas experiências prévias, sua compreensão do texto é mais profunda e ele consegue despertar aspectos tácitos por meio dessa leitura (ALEXANDER; JETTON, 2000). Sua construção cognitiva não parte do zero e ele é capaz de criar significações embasadas nas construções cognitivas que detém previamente que vão além do conteúdo explicitado na documentação.

\section{A MIOPIA DO CONTEÚDO DESCRITO PREESTABELECIDO}

Em contraposição ao que foi abordado anteriormente, existe o caso oposto ao conhecimento prévio. Nesse, o que está contido no documento pode também não ser compreendido pelo leitor pesquisador (GIL, 2009), pela formatação do documento ou mesmo por seu conteúdo.

A má interpretação de textos não advém apenas da falta de conhecimento de algumas palavras ou problemas físicos da documentação, tal como Rabinowitz (1987) deixa transparecer. O texto por si só não é suficiente para a interpretação completa do conteúdo do documento (STUBBS, 1996). Essa má compreensão faz com que o pesquisador não consiga extrair do documento todas as informações pertinentes à sua pesquisa.

Essa falta de compreensão por parte do leitor pode ter origem tanto da sua falta de conhecimento prévio quanto pelo próprio conteúdo dos documentos, que pode ser limitante. Esse problema é bastante usual em pesquisas que utilizam o método de análise de documentos porque eles, na grande maioria das vezes, não são preparados com o direcionamento de atender às pesquisas acadêmicas e, assim, os dados contidos neles não são suficientes para responder à pergunta de pesquisa do 
pesquisador (GIL, 2009). Diante dessa situação, o pesquisador fica preso a compreender, em termos de conteúdo, apenas o que está sendo transmitido pela escrita do documento. Portanto, em termos de conteúdo, o leitor somente consegue vislumbrar aquilo que está escrito.

Ainda em termos de conteúdo quantificável do documento, é relevante que o pesquisador se preocupe em buscar documentos em que se consiga verificar a veracidade das informações contidas. Ou seja, o pesquisador deveria buscar referências documentais que sejam as mais confiáveis possíveis, demonstrando em seu estudo quais são as possíveis limitações existentes nas escolhas de documentações a serem analisadas. Emerge-se dessa questão a importância em se selecionar documentos adequados e que possam valer os esforços de pesquisa por parte do pesquisador.

No âmbito da análise de conteúdo qualitativa, é importante ressaltar que o ato da leitura envolve interpretação do leitor, no caso, do pesquisador. Essa análise interna é, por natureza, qualitativa, dependendo, assim, das características dos valores e dos julgamentos do leitor para a realização da compreensão do conteúdo do documento.

Importantes considerações emergem: se, por um lado, defendeu-se aqui que o pesquisador tenha possibilidade de compreender um documento com significações e informações tácitas relevantes para sua construção cognitiva, que vão além do texto simbólico, por outro, em termos de conteúdo descrito, o investigador está limitado ao que está presente no documento. Não adianta o observador estar preparado para uma compreensão profunda do documento se o próprio documento, em si, é limitado de possíveis informações a serem coletadas. Por isso, é importante deixar claro o teor do processo quantitativo e do processo qualitativo do método de análise de documentos. O conteúdo quantitativo da análise documental é estático e fundamentado em testes objetivos de frequência. Porém, em contrapartida, o conteúdo qualitativo está presente de forma indireta, e depende das capacidades e da experiência do investigador para que essas informações sejam identificadas e levantadas na pesquisa acadêmica.

\section{A MIOPIA DA RETÓRICA}

Conforme já mencionado, um documento não é constituído apenas pelo seu conteúdo. Ele detém elementos qualitativos intrínsecos (elementos culturais do seu escritor e do contexto social no qual foi escrito, informações transmitidas por meio da abstração desenvolvida pelo conhecimento prévio do leitor, etc.) que não só fazem parte de seus atributos, como também podem trazer impactos ao leitor. Esse efeito pode ser de fundamental relevância para oferecer respostas para o pesquisador referentes ao fenômeno social envolvido no contexto do documento e às intenções contidos na sua elaboração.

Isso se justifica porque, quando um indivíduo é abordado por alguém, ele assume papéis, o que não é diferente em uma interação em que ele é abordado pelo pesquisador. Para Michener, DeLamanter e Myers (2003, p. 271), essa posição social adotada pelo pesquisado faz com que ele tenha uma postura de autoapresentação, que pode ser autêntica, ideal e tática. Nas palavras dos autores, essas formas de autoapresentação diferenciam-se da seguinte forma:

\footnotetext{
Na auto-apresentação autêntica, nossa meta é criar uma imagem de nós mesmos, aos olhos dos outros, que seja coerente com a maneira como nos enxergamos (nosso eu real). Na autoapresentação ideal, nosso objetivo é estabelecer uma imagem pública de nós mesmos, coerente com aquilo que desejamos ser (nosso eu ideal). Na auto-apresentação tática, nossa preocupação é estabelecer uma imagem pública de nós mesmos, coerente com aquilo que os outros desejam ou esperam de nós.
}

Assim, na autoapresentação tática, o pesquisado transpõe aquilo que quer transmitir. A justificativa mais comum para essa ação é a tentativa de imposição de papéis por parte do ator social, tal como defendem Weinstein e Deutschberger (1963). Essa postura pode ir além do contexto de uma abordagem científica entre pesquisador-pesquisado, valendo também para as interações sociais cotidianas na organização. Não obstante, essa postura pode ser colocada em vigor quando o gestor ou o funcionário assume papel de representantes da organização, havendo situações em que defende a imagem não apenas sua, mas também de toda a organização.

Essa abordagem de interação social pode ser transposta para os documentos elaborados por esses indivíduos, atores do ambiente social organizacional, porque os documentos podem ser o meio de comunicação entre os atores e gerar resultados sociais. 
O pesquisador acaba limitado a uma situação em que os documentos a que têm acesso, geralmente, são documentos contidos de retóricas. Essa limitação ocorre por duas razões principais: na primeira, o pesquisador pode apelar aos documentos públicos, que, por serem direcionados ao público aberto externo à organização, têm como objetivo transmitir a imagem organizacional pretendida desde a elaboração do documento; na segunda, a ética do pesquisador faz com que ele só acesse os documentos que Ihe forem viabilizados. É fundamental haver a autorização para se analisar um registro da organização: "a permissão para se examinar os arquivos deve ser solicitada" (MARTINS, 2008, p. 46). Ou seja, de um jeito ou de outro, os documentos os quais o pesquisador tem acesso, na maioria das vezes, são aqueles aos quais a organização permite o acesso, o que faz com que elementos que Ihe sejam favoráveis não sejam facilmente disponibilizados para análise.

Por isso, quando se transpõe essa intenção de criar uma percepção favorável aos leitores de um documento, pode existir uma realidade não representada no documento e à qual o pesquisador pode se aprofundar para compreender. Cabe a ele criar mecanismos e ferramentas de análise documental capaz de lhe fazer compreender o contexto e as intenções da elaboração do documento analisado ${ }^{2}$. Dessa forma, ele pode entender por completo as informações que estão implícitas no documento e que podem ser essenciais como resultados de sua pesquisa e, consequentemente, nas suas conclusões.

Assim, quando se fala de documentos corporativos oficiais, é importante estar atento para entender que eles não apenas contêm retóricas, mas retóricas que são constantemente revisadas antes de sua publicação. Essa cautela facilita que o pesquisador absorva todas as informações contidas no documento, sejam elas explícitas ou implícitas.

No mais, pode haver ainda um viés por parte do autor nas apresentações de documentos que ele próprio desconhece. Documentos organizacionais oficiais podem não conter dados de todo universo que ele representa, pelo fato de haver dados que ele não foi capaz de abranger. Gil (2009) cita o exemplo dos relatórios referentes aos dados de criminalidade que não contemplam a situação real da violência, já que crimes não reportados pelas vítimas são desconsiderados.

\section{A MIOPIA DO DOCUMENTO COMO FONTE ÚNICA DE DADOS}

Sabe-se também que a retórica pode estar contida não apenas nos documentos organizacionais, mas também nos discursos dos gestores da organização. Nesse sentido, vale lembrar que documentos, dependendo de sua natureza, podem ser uma boa forma também de se tentar compreender a validade desses discursos. A confiabilidade da percepção do fenômeno social é aumentada porque, muito raramente, os documentos são preparados para o estudo de caso científico realizado (YIN, 2008), o que dá margem ao pesquisador para coleta de dados não mascarados ou preparados exclusivamente para uma pesquisa acadêmica. $O$ uso da análise de documentos é limitante não apenas pelo teor das informações contidas neles, mas também porque é recomendável que o pesquisador muna-se de outras formas de coleta de dados que não a análise de documentos. É importante ter em mente que diferentes métodos científicos não necessariamente se anulam ou são concorrentes, mas podem também ser complementares e, portanto, triangulados (JICK, 1979). Assim, a análise de documentos como elemento único e central da coleta de dados qualitativos não é vista como algo completo, e sim complementar por diversos estudiosos.

Godoy (1995, p. 67) concorda que: "a análise de documentos constitui-se em uma valiosa técnica de abordagem de dados qualitativos, podendo também ser utilizada para complementar informações obtidas em outras fontes". Concomitantemente, Martins (2008, p. 46) afirma que "a realização de pesquisa documental é necessária (...) para corroborar evidências coletadas por outros instrumentos e outras fontes, possibilitando a confiabilidade de achados por meio de triangulação de dados e de resultados". Nessa mesma linha de pensamento, Gil (2009, p. 78) expõe essa característica complementar dos documentos a outros métodos de coleta de dados, aplicando também a ideia especificamente às publicações corporativas, dizendo que "mesmo não se referindo diretamente ao tópico da pesquisa, podem fornecer informações relevantes".

Essa conciliação com outras formas de coleta de dados daria maior validade ao documento, no momento de confrontá-lo com a realidade na qual a organização está imersa. Isso se aplica, por 
exemplo, ao realizar uma entrevista com um gestor: um documento corporativo pode servir como sustentação, complemento ou contraponto ao que foi coletado na entrevista, servindo de evidência para confirmações e análises do pesquisador.

Acrescentando-se a isso, ainda que a análise documental possa (e em alguns casos deva) ser complementada por outra forma de análise ou outro método de coleta de dados, por vezes, essa complementaridade pode acontecer com outra análise documental para fortalecer ambas as análises. Zikmund (2003) defende essa confrontação de dados considerando que dados provenientes de documentos são dados secundários que necessitam de um cross-check para que sua veracidade e sua validade sejam testadas. O autor destaca a relevância que se tem na preocupação em conferir esses dados provenientes de documentos porque eles podem conter informações enviesadas quando são produzidos internamente na organização. Portanto, sempre que possível, quando existem outras fontes de dados capazes de sustentar uma validação dos dados coletados, é interessante que a análise de documentos seja complementada.

Assim, tem-se, nas ciências sociais, e, portanto, nos estudos das organizações, um contexto em que o mais usual é que as pesquisas documentais estejam acompanhadas por métodos de coleta de dados, como a observação, as entrevistas ou as discussões em grupo (RITCHIE; SPENCER, 1994). Essa realidade traz algumas reflexões relevantes para discussão. Por um lado, a análise de documentos pode não ser considerada a única fonte para coleta de dados de campo, dado que ela apresenta limitações que podem ser supridas com métodos de coleta de dados. Por outro lado, e paradoxalmente, a análise de documentos não pode ser desprezada como pano de fundo para outros métodos científicos pelos pesquisadores (SILVERMAN, 2009).

Esses fatores levam a crer que a análise de documentos é vista como um método de coleta de dados que atua paralelamente a outra abordagem de campo, no entanto, isso não quer dizer que ela é submissa a outro método. As informações coletadas devem ser complementares, em vez de ser apenas confirmatórias. Nesse sentido, a análise de documentos não deveria assumir um papel maior do que ela realmente tem e, ao mesmo tempo, não deveria ser menosprezada pela falta de preparo do pesquisador em compreender o conteúdo e o contexto da criação do documento.

Ainda sendo vista de forma complementar em uma pesquisa de campo, a análise prévia de documentos relevantes da organização pode servir também de base para guiar perguntas e o próprio roteiro de uma posterior entrevista (PATTON, 2002). Ela serviria para preparar um método de coleta de dados principal, deixando-o mais robusto e sustentando em sua posterior aplicação.

Portanto, é importante que o pesquisador lembre-se de que sua pesquisa pode ter como fonte de dados quantas fontes forem relevantes e de possível acesso ao pesquisador, o que vale para a utilização de documentos. Eles podem ser complementares (e complementados) conforme a disponibilidade e a acessibilidade de fontes de dados que o pesquisador é capaz de obter. Sugerese que o pesquisador adote esse direcional, não considerando que a análise de documentos é um método complementar por ser insuficiente e fraca no fornecimento de dados, mas sim que, quando utilizada como complemento a outros métodos, é porque o contexto da sua pesquisa indica ser mais adequado usá-la em conjunto com outros métodos.

\section{DISCUSSÕES FINAIS}

A partir do levantamento dos elementos constituintes da análise de documentos, pôde-se perceber que o uso desse método requer cuidados. Nesse sentido, o presente estudo pretendeu evidenciar as limitações da análise documental para que sejam mais claros os pontos de cuidado que possam prejudicar a busca por robustez desse método de pesquisa. Fortalece-se e valoriza-se assim a análise de documentos como fonte de dados importantes para a pesquisa em organizações.

Por isso, tentou-se refletir também sobre quais poderiam ser as razões para uma possível preferência por outros métodos de pesquisa. As respostas podem ser estipuladas em três proposições. Primeiramente pelos diversos aspectos limitantes que o método traz consigo, tal como denotado ao longo do presente estudo. Em uma segunda perspectiva, porque eles não estão em evidência nas discussões acadêmicas, e por isso, na maioria das vezes, tampouco é considerado um 
método inovador para as pesquisas de campo. Na busca acadêmica por contribuições dos estudos, os pesquisadores podem preferir métodos mais recentes e menos explorados, como algo novo no contexto da pesquisa. Nesse mesmo pensamento, pode existir ainda uma rejeição por parte dos chamados gate keepers em entender a análise documental como um método robusto frente às possibilidades que as ciências sociais e humanas desenvolveram para pesquisas empíricas ao longo do tempo. Por fim, o próprio pesquisador pode julgar ser mais valioso ao seu estudo fazer por ele mesmo o levantamento de dados da sua pesquisa, preferindo apelar para coleta de dados primários e não recorrer aos dados documentais (dados secundários)3.

Entretanto, isso não quer dizer que a análise de documentos não seja capaz de fortalecer os estudos das organizações ou, ainda, que não tenha contribuições relevantes para as pesquisas de campo da área. Ela pode ser um método de confirmação daquilo que foi observado e levantado por meio de outros métodos; ou como forma de apontar inconsistências entre o que é proposto formalmente em documentos e o que ocorre em discursos falados ou no próprio cotidiano organizacional. No entanto, é importante que o pesquisador esteja ciente de que ela, por si só, como ferramenta central e única de pesquisa, tem suas limitações para o entendimento de fenômenos sociais e organizacionais. O pesquisador deve manter cautela para que essa forma de coleta de dados não assuma um papel maior que realmente tem. Por isso, para cada uma das principais limitações abordadas, o pesquisador pode apresentar os métodos complementares de coleta de dados, como apresentado no Quadro 1, para oferecer maior robustez à sua coleta de dados e, assim, obter validação das informações identificadas em campo.

Quadro 1 - Atividades complementares à análise de documentos para coleta de dados

\begin{tabular}{ll}
\hline $\begin{array}{l}\text { Miopias da análise de } \\
\text { documentos }\end{array}$ & Atividade de pesquisa complementar \\
\hline Miopia do contexto social & $\begin{array}{l}\text { Inserção do pesquisador no contexto social da organização para que ele } \\
\text { possa, na imersão social, compreender o contexto no qual os documentos } \\
\text { foram gerados e colher informações relevantes que influenciaram } \\
\text { a construção do documento e, consequentemente, as informações } \\
\text { coletadas empiricamente. }\end{array}$
\end{tabular}

Miopia do conhecimento prévio
Preparação prévia para a pesquisa de campo, no sentido de inteirar-se das formatações e do conhecimento aplicado aos documentos, para que o pesquisador consiga abstrair maior quantidade de informações (principalmente implícitas) do documento.
Miopia do conteúdo preestabelecido
Além de utilizar-se de informações contidas nos documentos, o pesquisador pode adotar outros métodos de campo, como a entrevista com os elaboradores do documento ou a observação do fenômeno ao qual o documento se refere, para compreender informações adicionais àquelas escritas.

Entendimento das operacionalizações e das atividades rotineiras das organizações para compreender se o que está escrito é uma imagem construída de como a organização pretende ser vista. Para

Miopia da retórica essa compreensão, sugere-se a observação das atividades cotidianas (inserção na organização) ou no mapeamento das atividades e dos pontos críticos dos processos para validar as informações coletadas no documento.

Miopia da fonte única de dados
Adoção de outros métodos complementares de coleta de dados que o pesquisador julgue relevante para validar e confrontar as informações coletadas por meio do documento.

Diante disso, é importante compreender que a análise de documentos é uma maneira de se coletar dados empíricos que possam dar maior robustez ao estudo empírico realizado. Entretanto, isso não isenta o pesquisador de realizar sua avaliação prévia do contexto e do objeto de estudo, a fim de levantar suas possibilidades e decidir quais são suas escolhas metodológicas frente à problemática de pesquisa. O que se recomenda é que o pesquisador defenda suas escolhas metodológicas, apresentando as razões pelas quais ele escolheu determinada abordagem metodológica, o que pode 
incluir a análise de documentos. Ou seja, quando o pesquisador for a campo com o intuito de realizar uma análise de documentos, o ideal é que ele justifique o porquê da escolha desse método e que exponha suas características, mesmo que isso acarrete limitações ao seu estudo.

Importante ainda é retomar que todo documento elaborado em uma organização é desenvolvido dentro de um contexto e está, portanto, inserido em um tempo e em um espaço específicos de criação. O documento contém elementos da organização que, ao mesmo tempo em que pode servir de pistas e informações coletadas pelo pesquisador, representa uma simbologia própria da organização, de modo que os valores da empresa estão inseridos de forma indireta no documento. Não se podem descartar nem ignorar informações que podem auxiliar no conjunto de dados levantados pelo pesquisador.

Aliando-se isso à ideia de que, quando se tenta estudar uma organização, por natureza, muitas considerações da interação social existentes nesse ambiente podem ser analisadas: o pesquisador tem como preocupação os resultados emergentes dessas interações e desse ambiente social influenciador. Não é diferente com os documentos corporativos. Por mais que a análise de documentos não se caracterize por uma interação social entre pesquisado e pesquisador, os documentos organizacionais podem trazer em seu bojo a intenção de provocar resultados sociais, tal como o estabelecimento de impressões de projeção de identidade.

Isso implica que a análise de documentos requer preparo e experiência por parte do pesquisador para melhor compreender as informações que o documento pode transmitir. Esse preparo envolve técnicas para compreensão de textos escritos para interiorização de conhecimentos que possam vir implícitos e codificados no documento. Como todo documento tem um objetivo quando é desenvolvido, que o faz moldar-se nesse direcionamento, a preparação do pesquisador requer que ele compreenda esse contexto para entender as limitações e as informações adicionais que o documento oferece e os motivos pelos quais ele lhe pode ser útil.

Com essas observações, estabelecem-se contribuições para os estudos das organizações quando: (1) se estabelece, em um mesmo plano, uma sistemática da análise de documentos, que pode oferecer ao pesquisador uma estrutura do processo de análise de documentos e que, consequentemente, pode dar maior compreensão sobre os documentos e suas informações; (2) se listam os principais problemas desse método de coleta de dados e se oferecem meios complementares pelos quais o pesquisador pode dar maior rigor às suas informações de campo coletadas; (3) se considera o documento como um elemento socialmente construído no contexto organizacional e quando se oferecem os devidos cuidados relativos a essa natureza.

Por fim, nenhum pesquisador quer ler um documento de forma míope, quando somente consegue enxergar o que lhe salta aos olhos, sem ver além do que está explicitamente exposto no texto do documento. Por isso, todos os documentos utilizados em pesquisas científicas deveriam ser vistos por meio das lentes da compreensão e da interiorização da dimensão tácita contida no documento por parte do pesquisador. Ter sensibilidade e capacidade para absorver esse tipo de informação requer experiência e conhecimentos prévios do pesquisador, portanto, a análise de documentos demanda pesquisadores profissionais qualificados frente a uma análise que, quando feita adequadamente, não é trivial e tem resultados que vão além da percepção superficial. Este é o papel do pesquisador: ser o intermediador dessa tradução para o público de sua pesquisa e compreender de forma mais profunda e completa os fenômenos organizacionais.

Por mais que o presente artigo pareça reforçar as miopias e as limitações da análise de documentos, ele não é contra o método abordado. Pelo contrário, tem-se o intuito de caminhar em direção do fortalecimento do método, em prol de sua utilização nas pesquisas dos estudos das organizações. No entanto, defende-se sua aplicação com rigor e, assim, valorizando-o. É obrigação dos estudiosos da área instituir maior rigor para a aceitação de pesquisas de documentações, assim como compreender que pesquisas documentais têm seu valor dentro dos anseios científicos dos estudos das organizações.

\section{LIMITAÇÕES E SUGESTÕES PARA ESTUDOS FUTUROS}

A limitação do presente estudo é que a identificação das miopias foi realizada de forma teórica, conforme levantamento realizado pelos autores, não se apoiando em um levantamento empírico de 
problemas identificados nos estudos realizados por meio da análise de documentos. Isto é, não se pôde ir a campo para se verificar se as informações e as tipologias aqui levantadas são capazes de completar todas as possibilidades de problemas e miopias da análise dos documentos. Realizar um levantamento dos problemas enfrentados no campo seria uma maneira de buscar validação das informações aqui apresentadas. Essa validação é importante para se sustentar empiricamente as considerações aqui abordadas e exemplificar as miopias identificadas por meio da revisão de literatura. Por isso, sugerese um subsequente esforço de pesquisa direcionado a observar os pontos aqui discutidos, de forma a validar as informações de um documento, além de apontar soluções práticas utilizadas para dirimir (ou, ao menos, diminuir) os problemas da sistemática da análise de documentos.

Propõe-se, ainda, que se realize uma bibliometria em uma amostra significativa de estudos de organizações que utilizaram a análise de documentos para identificar quais são os tipos de resultados obtidos por meio desse método de coleta de dados. Assim, podem-se aplicar aos casos da amostra quais são as miopias presentes em cada um dos artigos. Com isso, podem-se identificar não apenas quais são as miopias mais frequentes nos estudos das organizações, mas também se consegue correlacionar a presença de determinadas miopias com os tipos de estudos e com as áreas do conhecimento da Administração.

\section{REFERÊNCIAS}

ALEXANDER, P. A.; JETTON, T. L. Learning from text: a multidimensional and developmental perspective. In: M. L. KAMIL; P. B. MOSENTHAL; P. D. PEARSON; R. BARR (Orgs.). Handbook of Reading Research. Volume III. Mahwah: Lawrence Erlbaum Associates, 2000.

ALTHEIDE, D.; COYLE, M.; DEVRIESE, K.; SCHNEIDER, C. Emergent qualitative document analysis. In: S. M. HESSE-BIBER; P. LEAVY (Orgs.). Handbook of emergent methods. New York: Guilford Press, 2010.

ÁlVARO, J. L.; GARRIDO, A. Psicologia social. Perspectivas psicológicas e sociológicas. São Paulo: McGraw-Hill, 2006.

BAUMAN, Z. Afterthought. On writing; on writing sociology. In: N. K. DENZIN; Y. S. LINCOLN (Orgs.). The landscape of qualitative research. 3. ed. Thousand Oaks: Sage, 2008.

BERNARD, H. R.; RYAN, G. W. Text analysis. Qualitative and quantitative methods. In: H. R. BERNARD (Org.). Handbook of Research Methods in Cultural Anthropology Qualitative Research. Walnut Creek: AltaMira Press, 1998.

BERTERO, C. O.; CALDAS, M. P.; WOOD JR., T. Introdução: Produção científica em Administração no Brasil. In: C. O. BERTERO; M. P. CALDAS; T. WOOD JR. (Orgs.). Produção científica em Administração no Brasil. São Paulo: Atlas, 2005.

BOWEN, G. A. Document analysis as a qualitative research method. Qualitative Research Journal, v. 9, n. 2, p. 27-40, 2009.

CAMPOMAR, M. C. Do uso de "estudo de caso" em pesquisas para dissertações e teses em Administração. RAUSP (Revista de Administração da USP), v. 26, n. 3, p. 95-97, 1991.

CASEY, R. G.; WONG, K. Y. Document-analysis systems and techniques. In: R. KASTURI; M. M. TRIVEDI (Orgs.). Image analysis applications. New York: CRC Press, 1990.

DELLAGNELO, E. H. L.; SILVA, R. C. Análise de conteúdo e sua aplicação em pesquisa na Administração. In: M. M. F. VIEIRA; D. M. ZOUAIN (Orgs.). Pesquisa qualitativa em Administração. Teoria e prática. 2. ed. Rio de Janeiro: Editora FGV, 2007.

DWYTHER, G.; POSSAMAI-INESEDY, A. Methodologies a la carte: An examination of emerging qualitative methodologies in social research. International Journal of Social Research Methodology, v. 12, n. 2, p. 99-115, 2009.

FIOL, C. M. Corporate communications: comparing executive's private and public statements. Academy of Management Journal, v. 38, n. 2, p. 522-536, 1995.

GADAMER, H. G. Hermeneutics and social sciences. Philosophy \& Social Criticism, v. 2, n. 4, p. 307$316,1975$. 
GENTNER, D.; BOWDLE, B. F.; WOLFF, P.; BORONAT, C. Metaphor is like analogy. In: D. GENTNER; K. J. HOLYOAK; B. N.: KOKINOV (Orgs). The analogical mind. Perspectives from cognitive science. Boston, Estados Unidos: The MIT Press, 2001.

GIL, A. C. Estudo de caso. Fundamentação científica. Subsídios para coleta e análise de dados. Como Redigir o Relatório. São Paulo: Atlas, 2009.

GODOY, A. S. A pesquisa qualitativa e sua utilização em Administração de Empresas. RAE (Revista de Administração de Empresas), v. 35, n. 4, p. 65-71, 1995.

HOCAYEN DA SILVA, A. J.; ROSSONI, L.; FERREIRA JR., I. Administração pública e gestão social: a produção científica brasileira entre 2000 e 2005. Anais do II EnAPG (Encontro de Administração Pública e Governança, São Paulo, SP, Brasil, 2, 2006.

JICK, T. D. Mixing qualitative and quantitative methods: triangulation in action. Administrative Science Quarterly, v. 24, n. 4, p. 602-611, 1979.

KIESER, A.; LEINER, L. Why the rigour-relevance gap in management research is unbridgeable. Journal of Management Studies, v. 46, n. 3, p. 516-533, 2009.

KRIPPENDORFF, K. Content analysis. An introduction to its methodology. 2. ed. Thousand Oaks: Sage, 2004.

LEVY, D. M. Topics in document research. Anais do ACM Conference on Document Processing System, Santa Fe, Estados Unidos, 1, 1988

MANNING, P. K.; CULLUM-SWAN, B. Narrative, content, and semiotic analysis. In: N. K. DENZIN; Y. S. LINCOLN (Orgs.). Collecting and interpreting qualitative materials. Thousand Oaks: Sage, 1998.

MARTINS, G. A.; THEÓPHILO, C. R. Metodologia da investigação científica para ciências sociais aplicadas. São Paulo: Atlas, 2007.

MARTINS, G. A. Estudo de caso. Uma estratégia de pesquisa. 2. ed. São Paulo: Atlas, 2008.

MiCheneR, H. A.; Delamanter, J. D.; MYERS, D. J. Psicologia social. São Paulo: South-Western / Thomson, 2003.

MORGAN, G. More on metaphor: why we cannot control tropes in administrative science. Administrative Science Quarterly, v. 28, n. 4, p. 601-607, 1983.

ØSTERLUND, C.; BOLAND, R. J. Document cycles: knowledge flows in heterogeneous healthcare information systems environment. Anais do Hawaii International Conference on Systems Science, Big Island, Estados Unidos, 42, 2009.

PATTON, M. Q. Qualitative research \& evaluation methods. 3. ed. Thousand Oaks: Sage, 2002.

POZZEBON, M.; FREITAS, H. M. R. Pela aplicabilidade - com um maior rigor científico - dos estudos de casos em sistemas de informação. RAC (Revista de Administração Contemporânea), v. 2, n. 2, p. 143-170, 1998.

POZZEBON, M.; FREITAS, H. M. R.; PETRINI, M. Pela integração da inteligência nos Enterprise Information Systems (EIS). Ciência da Informação, v. 26, n. 3, p. 243-254, 1997.

PRIOR, L. Doing things with documents. In: D. SILVERMAN (Org.). Qualitative research. Theory, method and practice. $2^{\mathrm{a}}$ Ed. London: Sage, 2004.

PRIOR, L. Researching documents. Emerging methods. In: S. M. HESSE-BIBER; P. LEAVY (Orgs.). Handbook of emergent methods. New York: Guilford Press, 2010.

RABINOWITZ, P. J. Before reading. Narrative conventions and the politics of interpretation. Columbus: Ohio State University Press, 1987.

RITCHIE, J.; SPENCER, L. Qualitative data analysis for applied policy research. In: A. BRYMAN; R. G. BURGESS (Orgs.). Analyzing qualitative data. London: Routledge, 1994.

ROESCH, S. M. A. Quem responde pelo desempenho limitado da produção científica em Administração no Brasil? In: C. O. BERTERO; M. P. CALDAS; T. WOOD JR. (Orgs.). Produção científica em Administração 
no Brasil. São Paulo: Atlas, 2005.

ROSSONI, L.; HOCAYEN DA SILVA, A. J. Administração da Informação: A produção científica brasileira entre 2001 e 2006. Anais do EnADI (Encontro de Administração da Informação), Florianópolis, SC, Brasil, 1, 2007.

SALMINEN, A., KAUPPINEN, K.; LEHTOVAARA, M. Towards a methodology for document analysis. Journal of the American Society for Information Science, v. 48, n. 7, p. 644-655, 1997.

SALMINEN, A.; LYYTIKAINEN, V.; TIITINEN, P. (2000). Putting documents into their work context in document analysis. Information Processing \& Management, v. 36, n. 4, p. 623-641, 2000.

SILVERMAN, D. Interpretação de dados qualitativos. Métodos para análise de entrevistas, textos e interações. 3. ed. Porto Alegre: Bookman, 2009.

SOBRAL, F. J. B. A.; MANSUR, J. A. Produção científica brasileira em comportamento organizacional no período 2000-2010. RAE (Revista de Administração de Empresas), v. 53, n. 1, p. 21-34, 2013.

STABLEIN, R. Dados em Estudos Organizacionais. In: S. R. CLEGG; C. HARDY; W. R. NORD (Orgs.). Handbook de Estudos Organizacionais. Reflexões e novas direções. Vol. 2. São Paulo: Atlas, 2001.

STAKE, R. E. Case studies. In: N. K. DENZIN; Y. S. LINCOLN (Org.). Handbook of qualitative research. London: Sage, 2000.

STUBBS, M. Text and corpus analysis. Computer-assisted studies of language and culture. London: Blackwell, 1996.

SUTTON, R. I. The virtues of closet qualitative research. Organization Science, v. 8, n. 1, p. 97-106, 1997.

WEINSTEIN, E. A.; DEUTSCHBERGER, P. Some dimensions of altercasting. Sociometry, v. 26, n. 4, p. 454-466, 1963.

WHITLEY, R. The scientific status of management research as practically-oriented social science. Journal of Management Studies, v. 21, n. 4, p. 369-390, 1984.

YIN, R. K. Study case research. Design and methods. 4. ed. Thousand Oaks: Sage, 2008.

ZIKMUND, W. G. Business research methods. 7. ed. Mason: Thomson South-Western, 2003.

NOTAS

1 A metáfora da miopia parte do seu sentido literal cujo significado reside na limitação visual da qual o indivíduo não consegue enxergar de longe, apenas de perto, aplicado metaforicamente para o contexto da análise de documentos em que o leitor (pesquisador) pode apenas enxergar de perto, sem conseguir ver além, com maior profundidade o conteúdo do documento. Justifica-se o apelo às metáforas porque elas são linguagens estruturais que orientam a compreensão humana no entendimento de algo conforme a relação que se constrói por meio da experiência sobre outro significado conhecido. Ou seja, elas desenvolvem um significado pela compreensão de um fenômeno por meio do prévio entendimento de outro (MORGAN, 1983) em um processo de analogia e similaridade entre dois objetos (GENTNER et al., 2001).

2 Uma sugestão de ferramenta que o pesquisador pode utilizar é a observação do contexto social ou a entrevista com membros da organização que possa validar e oferecer maior profundidade de sentidos às informações coletadas pelos documentos.

3 Por mais que a discussão aqui apresente subsídios diretos apenas para a primeira perspectiva, isso não exclui que se estabeleçam proposições das possíveis causas da marginalização da análise documental. 